Communication

\title{
A Valuation of the Restoration of Hwangnyongsa Temple in South Korea
}

\author{
Ju-Hee Kim, Ga-Eun Kim and Seung-Hoon Yoo* \\ Department of Energy Policy, Graduate School of Energy \& Environment, Seoul National University of Science \\ \& Technology, 232 Gongreung-Ro, Nowon-Gu, Seoul 01811, Korea; jhkim0508@seoultech.ac.kr (J.-H.K.); \\ ogaeuno@naver.com (G.-E.K.) \\ * Correspondence: shyoo@seoultech.ac.kr; Tel.: +82-2-970-6802
}

Received: 30 November 2017; Accepted: 25 January 2018; Published: 31 January 2018

\begin{abstract}
Hwangnyongsa Temple (HT) in South Korea belongs to the Gyeongju Historic Areas, designated as a UNESCO World Heritage Site in 2000. The temple was destroyed by fire in AD 1238 and today there are few traces left, however the government is seeking to restore HT. This paper aims to evaluate the economic benefits of the restoration using contingent valuation (CV), and to then perform a cost-benefit analysis of the restoration. For this purpose, people's willingness to pay (WTP) for the restoration is elicited from a survey of 1000 households. The average household's WTP is estimated as KRW 2341 (USD 2.07) per annum. The current values of the benefits and costs of the restoration computed for the relevant period and population are KRW 415.3 billion (USD 366.9 million) and KRW 232.2 billion (USD 205.1 million), respectively. As the former is more than the latter, the restoration is socially profitable.
\end{abstract}

Keywords: Hwangnyongsa Temple; contingent valuation; willingness to pay; cost-benefit analysis

\section{Introduction}

Hwangnyongsa Temple (HT) is a representative legacy of the Gyeongju Historic Areas and East Asia's largest patriotic temple built over 93 years in the sixth century during the Silla Dynasty, a culture that endured for a millennium (BC 57 to AD 935). In particular, the 9-story wooden pagoda of HT was constructed using the sixth century's most superior building technique called the plate shaft method, which is observed in some ancient Asian cultural properties such as Horyusa 5-story wooden pagoda in Japan and is known to have been passed down from ancient Korea [1]. Though the plate shaft method is an excellent ancient architectural technique of Korean, it is mostly used for wooden buildings that can be easily damaged by natural disasters and fire, so that the prototype of the cultural heritage has not been preserved well. Therefore, its construction method was thought to be a mystery until several years ago because it was built $80 \mathrm{~m}$ tall without nails or cranes.

HT was destroyed by fire in the Koryeo Dynasty (AD 1238) and currently there are few traces left. Although HT has both great historical and engineering value, it is difficult for the public to recognize its historic and engineering value because most of the remains have been lost. Gyeongju Historic Areas is a representative cultural heritage site and the number of visitors each year has increased [2]. Local residents and researchers have prepared and longed for a long time to restore HT.

Therefore, the government is seeking to restore the HT by 2035 through a combination of historical records and modern engineering techniques. Overall, the restoration is made up of four steps: research, excavation and investigation, restoration, and maintenance.

Thus, the policy makers are demanding information about the public value of the restoration in order to make an informed decision concerning whether the restoration should be performed or not and how much value the restoration produces to the public. To this end, this paper tries to determine 
people's willingness to pay (WTP) for restoration. The WTP represents household preference for or acceptability of the restoration and implies public value of the restoration in an economic sense.

This paper seeks to assess the economic benefits of the restoration and then to conduct a cost-benefit analysis of the restoration. The benefits are measured by eliciting the public willingness to pay (WTP) for the restoration. The task of discovering the WTP can be conducted using contingent valuation (CV) [3-9]. Thus, this paper attempts to derive information about the public value or acceptability of restoring HT by 2035. To this end, the South Korean households' WTP for the restoration are elicited employing the $\mathrm{CV}$ approach. Moreover, a cost-benefit analysis of the restoration is performed. The rest of this paper is composed of four sections. Section 2 is devoted to describing the methodology adopted in this paper. Section 3 explains the WTP model employed in the paper. Section 4 provides and discusses the results. Conclusions are presented in the final section.

\section{Methodology}

\subsection{Methods: CV Method}

Specifically, this paper uses the CV approach and values the restoration of HT. The use of the CV method is consistent with the experience of some related former studies, since the method is most frequently adopted in the literature [3-9]. We can obtain a welfare measure easily by conducting a CV survey and then statistically looking into the data from the survey. As the value information derived from this study can be utilized in policy making and analysis, a derivation based on sound and reasonable methodology is quite important. The $\mathrm{CV}$ method is grounded in the theory of consumer choice in microeconomics. In particular, Noonan [10] reviewed the applications of CV in the cultural arena and revealed the consistency and validity of the use of the CV method in cultural applications.

Furthermore, lots of recommendations for the use of the CV method, which are given in Arrow et al. [11] and other relevant literature [12,13], are fully reflected in our study. For instance, the adoption of at least 1000 sample size, the use of a dichotomous choice (DC) question, the employment of annual payment as a payment vehicle, the presentation of substitutes for the goods of concern and the implementation of pretesting survey questionnaire were followed in our CV questionnaire.

\subsection{Sampling and Survey Instrument}

The sampling framework was based on the population characteristics found in Statistics Korea [14]. A supervisor affiliated with a professional polling firm took charge of the sampling and designed stratified random sampling. The CV survey was implemented during September 2017. The supervisor and we educated the interviewers in how to conduct the CV survey well. They visited the interviewees' houses, presented the survey questionnaire to them, and asked them to complete the survey questionnaire.

We tested an initial version of survey questionnaire carrying out a focus group interview of 30 persons in order to check its understandability and clarity for respondents, and were able to finalize the corrections and further refine the questionnaire. The finalized version of the CV survey instrument was structured in the following order. First, the purpose of the CV survey is explained and the background information is conveyed to help the respondents to understand the purpose. Second, some questions that asked about respondents' perceptions and judgments concerning the replacement are presented. Third, some questions on the WTP for restoring the HT in South Korea are provided to the respondents. Finally, some questions for obtaining information about the respondents' characteristics are asked.

\subsection{Elicitation of WTP}

This study utilizes a DC question method adopting Hanemann's [15] recommendation to gather the data on the households' WTP. Using the DC question, an incentive-compatible response can be derived from the respondent. Typically, a respondent is asked to answer whether she/he has 
willingness to pay a specified amount to restore the HT or not. The response is simply "yes" or "no". Usually, the DC question is used as one of two formats: a SB DC format or a DB DC format [15-17]. The SB DC format suffers from the statistical inefficiency because it asks just one question and thus we can use just one response. The DB DC format can increase the statistical efficiency relative to SB DC format since two questions required in the use of DB DC format can narrow the range of the WTP. However, the second question can cause a response bias, that is, inducing a false response to the second question [18].

In order to overcome the disadvantages involved in the use of SB DC format or DB DC format, Cooper et al. [19] suggested a new format of eliciting WTP response, OOHB DC format. This format can selectively utilize the advantages of the SB DC format and the DB DC format. Thus, it can increase statistical efficiency compared with a SB DC question and alleviate the response bias that can occur when using a DB DC question. In other words, the use of OOHB DC format can give us more efficient outcome than the use of SB DC format and less bias-inducing outcome than the use of DB DC format. In this regard, this study employs the OOHB DC format.

\subsection{Payment Vehicle}

The scenario and questions used in the CV survey are hypothetical, and thus the respondents may have difficulties in answering them. One powerful approach to avoid the problems arising from the hypothetical situation is to adopt an appropriate payment vehicle and then insert it into the CV questionnaire survey. The payment vehicle should possess some desirable properties such as persuasiveness, understandability, and familiarity to the respondents. This study used income tax as the payment vehicle because it is the most common in South Korea among several taxes. The WTP question was "If the restoration plan would certainly be implemented, are you willing to pay a given amount for restoring the HT in South Korea by 2035 through an increase in yearly income tax?".

\section{WTP Model}

\subsection{Basic OOHB DC Model}

$A_{j}$ means the bid presented to interviewee $j . Y_{j}$ indicates her/his WTP. We need to set two bids, $A_{j}^{L}$ and $A_{j}^{U}\left(A_{j}^{L}<A_{j}^{U}\right)$, prior to conducting the CV survey. When conducting field surveys, one among several sets is randomly distributed and then one of two bids is presented to interviewee $j$ as follows. Approximately half of the respondents received an $A_{j}^{L}$ and were asked to answer "yes" or "no" to the payment of $A_{j}^{L}$. Those who stated "yes" were additionally provided with $A_{j}^{U}$ and asked to say "yes" or "no" to $A_{j}^{U}$. If the response was "no", there was no further question. Likewise, the remaining half of the respondents were given $A_{j}^{U}$ and asked to report with "yes" or "no". One more question concerning $A_{j}^{L}$ was asked of those who responded "no". On the other hand, no further question was presented to those who responded "yes".

When $A_{j}^{L}$ was presented at first, the list of possible responses were "yes-yes" $\left(Y_{j}>A_{j}^{U}\right)$, "yes-no" $\left(A_{j}^{L}<Y_{j}<A_{j}^{U}\right)$, and "no" $\left(Y_{j}<A_{j}^{L}\right)$. When $A_{j}^{U}$ was offered at first, one of "yes" $\left(Y_{j}>A_{j}^{U}\right)$, "no-yes" $\left(A_{j}^{L}<Y_{j}<A_{j}^{U}\right)$, and "no-no" $\left(Y_{j}<A_{j}^{L}\right)$ could be observed. Consequently, six binary variables, $I_{j}^{Y Y}, I_{j}^{Y N}, I_{j}^{N}, I_{j}^{Y}, I_{j}^{N Y}$, and $I_{j}^{N N}$, are introduced. The value of each variable was defined as one when respondent $j$ 's response corresponded with its superscript and zero otherwise.

\subsection{OOHB DC Spike Model}

A respondent can report a zero WTP value when the restoration does not contribute to her/his utility, she/he cannot afford to pay some money for the restoration, or she/he is indifferent to the restoration. In this case, a WTP model that can deal with the zero WTP responses should be applied. This study uses the spike model $[20,21]$ for the purpose of analyzing the WTP data with zero values. An additional question identifying the respondents' WTP as a positive value less than the lower bid 
$\left(A_{j}^{L}\right)$ or zero was asked of the respondents who gave "no" or "no-no" responses. The question is "Would your household be willing to pay anything at all?" Her/his WTP is more than zero and less than the lower bid $\left(0<Y_{j}<A_{j}^{L}\right)$ if the answer is "yes" and zero otherwise. In this regard, one more binary variable, $I_{j}^{T Y}$, can be defined. Its value is one if respondent $j$ responded "yes" to the additional question and zero otherwise. Thus, a total of eight responses can emerge from our study that uses the OOHB DC spike model, as illustrated in Figure 1.

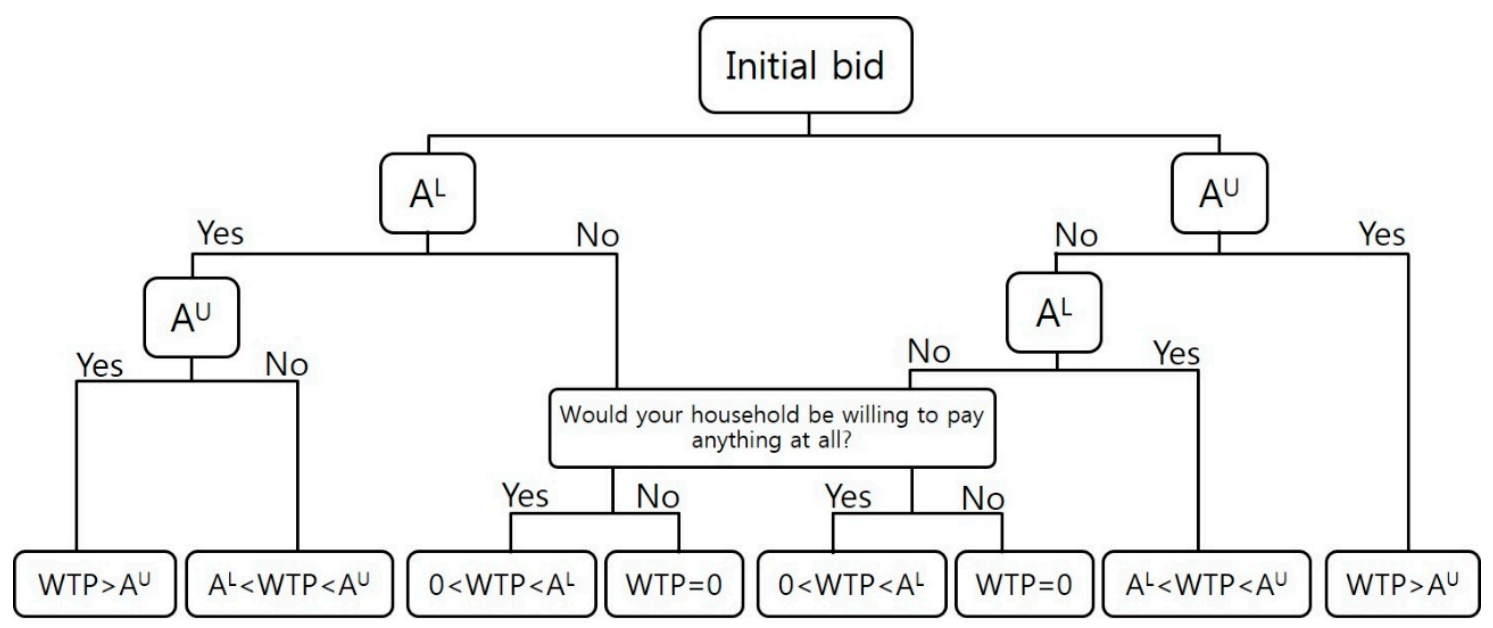

Figure 1. Procedures of eliciting the willingness to pay (WTP) responses in this study.

Let the distribution function of the WTP for the model be $H_{Y}(\cdot)$ where $\gamma_{0}$ and $\gamma_{1}$ are its parameters. It is formulated as:

$$
H_{Y}\left(A ; \gamma_{0}, \gamma_{1}\right)= \begin{cases}{\left[1+\exp \left(\gamma_{0}-\gamma_{1} A\right)\right]^{-1}} & \text { if } A>0 \\ {\left[1+\exp \left(\gamma_{0}\right)\right]^{-1}} & \text { if } A=0 \\ 0 & \text { if } A<0\end{cases}
$$

For the OOHB DC spike model, the log-likelihood function is specified as:

$$
\begin{aligned}
\ln L= & \sum_{j=1}^{T}\left\{I_{j}^{Y} \ln \left[1-H_{Y}\left(A_{j}^{U} ; \gamma_{0}, \gamma_{1}\right)\right]\right. \\
& +\left(I_{j}^{Y N}+I_{j}^{N Y}\right) \ln \left[H_{Y}\left(A_{j}^{U} ; \gamma_{0}, \gamma_{1}\right)-H_{Y}\left(A_{j}^{L} ; \gamma_{0}, \gamma_{1}\right)\right] \\
& +I_{j}^{T Y}\left(I_{j}^{N}+I_{j}^{N N}\right) \ln \left[H_{Y}\left(A_{j}^{L} ; \gamma_{0}, \gamma_{1}\right)-H_{Y}\left(0 ; \gamma_{0}, \gamma_{1}\right)\right] \\
& \left.+\left(1-I_{j}^{T Y}\right)\left(I_{j}^{N}+I_{j}^{N N}\right) \ln H_{Y}\left(0 ; \gamma_{0}, \gamma_{1}\right)\right\}
\end{aligned}
$$

If we use Equation (1) and a formula for computing the mean, the mean WTP can be derived as $\left(1 / \gamma_{1}\right) \ln \left[1+\exp \left(\gamma_{0}\right)\right]$.

\section{Results and Discussion}

\subsection{Results}

The list of bids is KRW 1000/3000, 2000/4000, 3000/6000, 4000/8000, 6000/10,000, 8000/12,000, and 10,000/15,000. When the CV survey was performed, USD 1.0 equaled KRW 1132. In all, 1000 usable observations were obtained. Table 1 describes the number of the responses corresponding to each bid. When the lower bid $\left(A_{j}^{L}\right)$ is presented as the first bid, "yes-yes", "yes-no", "no-yes", and "no-no" responses indicate $Y_{j}>A_{j}^{U}, A_{j}^{L}<Y_{j}<A_{j}^{U}, 0<Y_{j}<A_{j}^{L}$, and, $Y_{j}=0$, respectively. Similarly, when the higher bid $\left(A_{j}^{U}\right)$ is presented as the first bid, "yes", "no-yes", "no-no-yes", and "no-no-no" responses 
imply $Y_{j}>A_{j}^{U}, A_{j}^{L}<Y_{j}<A_{j}^{U}, 0<Y_{j}<A_{j}^{L}$, and, $Y_{j}=0$, respectively. A total of 644 households among sampled 1000 households gave zero WTP responses. Thus, $64.4 \%$ of the interviewees stated zero WTP for the restoration. This confirms that we need to apply the spike model.

Table 1. Distribution of responses by bid amount.

\begin{tabular}{lccccccccc}
\hline & \multicolumn{3}{c}{ Lower Bid Is Presented as the First Bid (\%) b } & \multicolumn{3}{c}{ Upper Bid Is Presented as the First Bid (\%) } \\
\hline \multicolumn{2}{c}{ Bid Amount } \\
\hline
\end{tabular}

Note: ${ }^{a}$ The unit is Korean won. At the time of the survey, USD 1.0 equaled KRW 1132. ${ }^{b}$ The figures in parentheses beside the number of responses are the percentage of sample size.

The estimation results of the model are contained in Table 2. The estimated coefficient for the bid amount is statistically significant. Its sign is negative, which means that the higher the bid amount, the greater the probability of an interviewee's reporting "yes" to a given bid amount. The estimate for the spike is 0.6500 . This value is close to the ratio of zero WTP responses in the sample $(64.4 \%)$. The Wald statistic implies the rejection of the hypothesis that the estimated equation is insignificant. The mean WTP for the restoration is computed to be KRW 2341 (USD 2.07) per annum. The confidence intervals for this value are also presented in Table 2. These are calculated by the use of Krinsky and Robb's approach [22].

Table 2. Estimation results of the model.

\begin{tabular}{|c|c|}
\hline Variables & Coefficient Estimates ${ }^{d}$ \\
\hline Constant & $-0.6190(-9.36)^{\#}$ \\
\hline Bid amount ${ }^{a}$ & $-0.1840(-16.44)^{\#}$ \\
\hline Spike & $0.6500(43.36)^{\#}$ \\
\hline $\begin{array}{l}\text { Mean WTP per household per year } \\
t \text {-value }\end{array}$ & $\begin{array}{c}\text { KRW } 2341 \text { (USD 2.07) } \\
13.81^{\#}\end{array}$ \\
\hline $95 \%$ confidence interval $\mathrm{b}$ & KRW 2039 to 2709 (USD 1.80 to 2.39 ) \\
\hline $99 \%$ confidence interval $^{b}$ & KRW 1961 to 2834 (USD 1.73 to 2.50 ) \\
\hline Sample size & 1000 \\
\hline Log-likelihood & -1034.34 \\
\hline Wald statistic ( $p$-value $)^{\mathrm{c}}$ & $190.71(0.000)$ \\
\hline
\end{tabular}

Notes: a The unit is KRW 1000. At the time of the survey, USD 1.0 equaled KRW 1132. ${ }^{\mathrm{b}}$ They are computed by the use of Krinsky and Robb's [22] approach. ${ }^{c}$ The null hypothesis is that the estimated equation is insignificant. $\mathrm{d}$ The $t$-values are reported in parentheses beside the coefficient estimates. " indicates statistical meaningfulness at the $1 \%$ level.

\subsection{Discussion of the Results}

As a final step of the analysis, we need to expand the sample information to the population information [11]. At the time of the survey, there were 21,455,795 households in South Korea [14]. Using this information, it can be determined that the total annual WTP is KRW 50.2 billion (USD 44.4 million) over the period 2017-2026. The cost of the restoration was KRW 332.9 billion over the period 2012-2035. The steps of research, excavation and investigation, restoration, and maintenance require KRW 4.2, 6.4, 253.0, and 69.3 billion, respectively. The social discount rate that the Korean government officially uses is $4.5 \%$. 
The present values of the benefits and costs of the restoration in 2017 are worth KRW 415.3 billion (USD 366.9 million) and KRW 232.2 billion (USD 205.1 million), respectively. It appears that the total WTP is more than the cost. The net present value, the ratio of benefit over cost, and the internal rate of return are estimated as KRW 183.1 billion (USD 134.7 million), 1.79\%, and 59.5\%, respectively, which exceed $0 \%, 1.0 \%$, and $4.5 \%$, respectively. In summary, the restoration is socially desirable. The government should push ahead with the restoration continuously.

\section{Conclusions}

The objective of this paper was to evaluate the economic benefits of restoring the HT until 2035 using the CV approach and conduct a cost-benefit analysis of the restoration. The average household WTP for the restoration was calculated as KRW 2341 (USD 2.07) per annum for the next ten years. This value had statistical meaningfulness at the $1 \%$ level. Using a social discount rate of $4.5 \%$ and a relevant evaluation period when the benefits and costs arise, the present values of the benefits and costs of the restoration were calculated to be KRW 415.3 billion (USD 366.9 million) and KRW 232.2 billion (USD 205.1 million), respectively. As the former is more than the latter, the restoration was socially desirable. Thus, we can conclude that the restoration is supported by the public and should be continuously carried out. The study added some evidence to the existing literature regarding whether restoring the HT passed the economic feasibility test.

Author Contributions: All the authors contributed significantly. Ju-Hee Kim conceived the ideas and analyzed the data; Ga-Eun Kim wrote the better part of the manuscript; and Seung-Hoon Yoo contributed the main idea and various scientific insights and helped to edit the manuscript.

Conflicts of Interest: The authors declare no conflict of interest.

\section{References}

1. Lee, D.U. Baekje Buddhism in world heritage of Japan. J. Won Buddhism Thought Relig. Cult. 2010, 8, 553-579. (In Korean)

2. Gyeongju City. 2030 Gyeongju City Basic Plan. 2017. Available online: http:/ / www.gyeongju.go.kr (accessed on 24 January 2017).

3. Salazar, S.D.S.; Marques, J.M. Valuing cultural heritage: The social benefits of restoring and old Arab tower. J. Cult. Heritage 2002, 6, 69-77. [CrossRef]

4. Lim, S.Y.; Park, S.Y.; Yoo, S.H. The environmental conservation value of the Saemangeum open sea in Korea. Sustainability 2017, 9, 2036. [CrossRef]

5. Choi, H.Y.; Kwak, S.J.; Yoo, S.H. The preservation value of the Bangudae Petroglphs, the 285th Korean National Treasure. J. Cult. Heritage 2016, 18, 380-383. [CrossRef]

6. Lim, S.Y.; Kim, H.Y.; Yoo, S.H. Public willingness to pay for transforming Jogyesa Buddhist Temple in Seoul, Korea into a cultural tourism resource. Sustainability 2016, 8, 900. [CrossRef]

7. Thompson, E.; Berger, M.; Blomquist, G.; Allen, S. Valuing the arts: A contingent valuation approach. J. Cult. Econ. 2002, 26, 87-113. [CrossRef]

8. Susilo, H.; Takahashi, Y.; Yabe, M. The opportunity cost of labor for valuing Mangrove restoration in Mahakam Delta, Indonesia. Sustainability 2017, 9, 2169. [CrossRef]

9. Lim, S.Y.; Jin, S.J.; Yoo, S.H. The economic benefits of the Dokdo Seals restoration project in Korea: A contingent valuation study. Sustainability 2017, 9, 968. [CrossRef]

10. Noonan, D.S. Contingent valuation and cultural resources: A meta-analytic review of the literature. J. Cult. Econ. 2003, 27, 159-176. [CrossRef]

11. Arrow, K.; Solow, R.; Portney, P.R.; Leamer, E.E.; Radner, R.; Schuman, H. Report of the NOAA panel on contingent valuation. Fed. Regist. 1993, 58, 4601-4614.

12. Johnston, R.J.; Boyle, K.J.; Adamowicz, W.; Bennett, J.; Brouwer, R.; Cameron, T.A.; Hanemann, W.M.; Hanley, N.; Ryan, M.; Scarpa, R.; et al. Contemporary guidance for stated preference studies. J. Assoc. Environ. Resour. Econ. 2017, 4, 319-405. [CrossRef]

13. Venkatachalam, L. The contingent valuation method: A review. Environ. Impact Assess. Rev. 2004, 24, 89-124. [CrossRef] 
14. Statistics Korea. Available online: http:/ / kosis.kr (accessed on 20 November 2017).

15. Hanemann, W.M. Welfare evaluations in contingent valuation experiments with discrete responses. Am. J. Agric. Econ. 1984, 66, 332-341. [CrossRef]

16. Hanemann, W.M.; Loomis, J.; Kanninen, B.J. Statistical efficiency of double-bounded dichotomous choice contingent valuation. Am. J. Agric. Econ. 1991, 73, 1255-1263. [CrossRef]

17. Bateman, I.J.; Langford, L.H.; Jones, P.; Kerr, G.N. Bound and path effects in double and triple bounded dichotomous choice contingent valuation. Resour. Energy Econ. 2001, 23, 191-213. [CrossRef]

18. Carson, R.T.; Flores, N.E.; Meade, N.F. Contingent valuation: Controversies and evidence. Environ. Resour. Econ. 2001, 19, 173-210. [CrossRef]

19. Cooper, J.C.; Hanemann, W.M.; Signorello, G. One and one-half bound dichotomous choice contingent valuation. Rev. Econ. Stat. 2002, 84, 742-750. [CrossRef]

20. Kriström, B. Spike model in contingent valuation. Am. J. Agric. Econ. 1997, 79, 1013-1023. [CrossRef]

21. Yoo, S.H.; Kwak, S.J. Using a spike model to deal with zero response data from double bounded dichotomous choice contingent valuation surveys. Appl. Econ. Lett. 2002, 9, 929-932. [CrossRef]

22. Krinsky, I.; Robb, A.L. On approximating the statistical properties of elasticities. Rev. Econ. Stat. 1986, 68, 715-719. [CrossRef]

(C) 2018 by the authors. Licensee MDPI, Basel, Switzerland. This article is an open access article distributed under the terms and conditions of the Creative Commons Attribution (CC BY) license (http:/ / creativecommons.org/licenses/by/4.0/). 